\title{
ESTIMATIVA DA TEMPERATURA DO AR MICROCLIMÁTICA EM CUIABÁ/MT UTILIZANDO REDES NEURAIS
}

\author{
PAULA, Diana Carolina Jesus de - arqdiana.paula@gmail.com \\ Universidade Federal do Mato Grosso / UFMT
}

GUARIENTI, César Eduardo - cesar.guarienti@ic.ufmt.br Universidade Federal do Mato Grosso / UFMT

GOMES, Raphael de Souza Rosa - raphael@ic.ufmt.br Universidade Federal do Mato Grosso / UFMT

\author{
SANTOS, Flávia Maria de Moura - flavia_mms@hotmail.com \\ Universidade Federal do Mato Grosso / UFMT
}

Submetido em: $18 / 07 / 2020$

Aceito para publicação em: 20/01/2021

Publicado em: 06/04/2021

DOI: http://dx.doi.org/10.5380/abclima.v28i0.75304

\begin{abstract}
RESUMO: Frente ao rigor climático característico de Cuiabá/MT, é importante acompanhar a evolução da intensidade das ilhas de calor noturnas encontradas no município, principalmente devido aos efeitos sentidos pela população. O objetivo deste artigo foi de estimar a temperatura do ar e posteriormente a ilha de calor urbana para 2021, utilizando Rede Neural Artificial. Os resultados evidenciam que o melhor modelo de outono apresentou $R^{2} 0,88$ e o de inverno obteve $R^{2} 0,97$, primavera obteve $R^{2} 0,94$ e o verão alcançou $R^{2}$ 0,99. As diferenças entre os dados de Temperatura do ar medidos e estimados nas estações variaram entre $0,01^{\circ} \mathrm{C}$ a $0,20^{\circ} \mathrm{C}$, indicando que em todos os modelos há alta relação entre os dados medidos e previstos. Os resultados observados apontam tendência de elevação da intensidade das ilhas de calor noturnas em todas as estações do ano na cidade, o que pode influenciar no aumento de casos de enfermidades pelo aumento da temperatura do ar, além da demanda de energia nas edificações.
\end{abstract}

PALAVRAS-CHAVE: Mudanças Climáticas, Climatologia urbana, Modelagem.

ESTIMATION OF MICROCLIMATIC AIR TEMPERATURE IN CUIABÁ / MT USING NEURAL NETWORKS

ABSTRACT: In view of the climatic rigor characteristic of Cuiabá / MT, it is important to monitor the evolution of the intensity of the night heat islands found in the municipality, mainly due to the effects felt by the population. The objective of this article was to estimate the air temperature and subsequently the urban heat island for 2021, using Artificial Neural Network. The results show that the best autumn model presented $\mathrm{R}^{2}$ 0.88 and the winter one obtained $R^{2} 0.97$, spring obtained $R^{2} 0.94$ and summer reached $R^{2}$ 0.99. The differences between the measured and estimated air temperature data in the stations ranged from $0.01^{\circ} \mathrm{C}$ to $0.20^{\circ} \mathrm{C}$, indicating that in all models there is a high relationship between the measured and predicted data. The observed results point to a tendency towards an increase in the intensity of night heat islands in all seasons of the year in the city, which may influence the increase in cases of illness due to the increase in air temperature, in addition to the energy demand in buildings.

KEYWORDS: Climate Change, Urban Climatology, Modeling. 

UTILIZANDO REDES NEURALES

RESUMEN: Dado el rigor climático característico de Cuiabá / MT, es importante monitorear la evolución de la intensidad de las islas de calor nocturno que se encuentran en el municipio, principalmente por los efectos que siente la población. El objetivo de este artículo fue estimar la temperatura del aire y posteriormente la isla de calor urbano para 2021, utilizando una Red Neural Artificial. Los resultados muestran que el mejor modelo de otoño presentó $R^{2} 0,88$ y el de invierno obtuvo $R^{2} 0,97$, la primavera obtuvo $R^{2} 0,94$ y el verano alcanzó $R^{2}$ 0,99. Las diferencias entre los datos de temperatura del aire medidos y estimados en las estaciones oscilaron entre $0.01^{\circ} \mathrm{C}$ y $0.20^{\circ} \mathrm{C}$, lo que indica que en todos los modelos existe una alta relación entre los datos medidos y pronosticados. Los resultados observados apuntan a una tendencia al aumento de la intensidad de las islas de calor nocturno en todas las estaciones del año en la ciudad, lo que puede influir en el aumento de casos de enfermedad por aumento de la temperatura del aire, además de la demanda energética en los edificios.

PALABRAS CLAVE: Cambio climático, climatología urbana, modelización.

\section{INTRODUÇÃO}

Segundo o quinto relatório de avaliação (AR5) do Painel Intergovernamental de Mudanças Climáticas (IPCC), a previsão do aumento da temperatura média global é de 2,6 a $4,8^{\circ} \mathrm{C}$ até o final do século. No entanto, conforme determina o Acordo de Paris, os países signatários ficam limitados a manter a temperatura média global abaixo de $2^{\circ} \mathrm{C}$ acima dos níveis industriais e promover esforços para limitar o aumento da temperatura média global a $1,5^{\circ} \mathrm{C}$ acima dos niveis pré-industriais.

Somente em 2014 o IPCC dedicou um capítulo especial sobre dados climáticos dedicado as cidades, evidenciando que os eventos climáticos extremos afetariam a maior parte da população nos centros urbanos (DUARTE, 2015). Dados publicados pela ONU (2019) afirmam que $55 \%$ da população mundial vive em áreas urbanas e, até 2050, este percentual deve chegar a $70 \%$. Evidenciam ainda que $40 \%$ das emissões de Gases do Efeito Estufa (GEE) estão relacionadas ao setor da construção civil.

O Painel Brasileiro de Mudanças Climáticas (PBMC, 2016), recomenda que o planejamento das cidades deve incluir 0 conhecimento das vulnerabilidades existentes e riscos associados à ocorrência de eventos extremos climáticos, devido aos altos custos associados ao desenvolvimento urbano. Evidencia que não agir em adaptação custará muito mais no futuro, sendo o ideal que as cidades sejam remodeladas e planejadas de acordo com as prioridades existentes, visando torná-las resilientes às mudanças climáticas.

Oke (1973) cita que a ocupação e a densidade construtiva alteram o ambiente microclimático, pois influenciam na temperatura do ar no nível do solo, afetam diretamente a magnitude e o regime de entrada (ondas curtas) e saída (ondas longas) de energia disponível para as trocas térmicas entre as superfícies e o céu (ABREU-HARBICH; LABAKI; MATZARAKIS, 2015). Assim a complexidade térmica encontrada na escala intraurbana, é resultado de um difícil equilíbrio entre o uso e ocupação do solo, e os fatores e elementos climáticos locais, regionais e globais. Portanto, estudos que visam o desenvolvimento de indicadores, ferramentas e modelos de avaliação sobre tais fatores é essencial para os estudos sobre o microclima (ROCHA \& SOUZA,2011). 
Neste sentido, muitas pesquisas com o objetivo de estimar, prever e simular cenários futuros a partir da temperatura do ar tem sido realizada em vários países, tendo como desafio as anomalias térmicas, que ocorrem dentro dos ambientes urbanos. Como a ilha de calor urbana (ICU), que é definida a partir da diferença de temperatura do ar observada dentro da área urbana (OKE, 1987).

As ilhas de calor, especialmente no verão, diminuem consideravelmente a qualidade do ar externo e desencadeiam doenças e mortes relacionadas ao calor nas áreas urbanas. Além disso, à elevação das temperaturas urbanas acarretam o aumento no uso do sistema de ar condicionado, consequentemente a demanda de eletricidade e consumo de energia dos edifícios aumentam (BASU, 2002; DOYON et al., 2008; BASU, 2009; PARAVANTIS et al., 2017)

Devido aos efeitos das ilhas de calor urbanas (ICU), atenções foram direcionadas ao desenvolvimento de modelos preditivos de ICU orientados a dados que podem prever a ICU em um determinado momento no futuro (OH et al, 2020). Desta maneira a escolha pela Inteligência Artificial (IA) deve-se a exploração de um grande volume dados para predição envolvendo algoritmos de aprendizagem, assim o aprendizado de máquina ou Machine Learning ((ML) pode ser utilizado na área ambiental, bem como na predição da temperatura do ar (LOPES et al., 2017)

No entanto, se faz necessário apresentar as vantagens em comparações com outros modelos estatísticos, com isso apresentam-se as Redes Neurais Artificiais (RNA), que tem sido um instrumento cada vez mais eficiente na previsão de cenários futuros, pela capacidade de processamento de um grande volume de dados, precisão e acurácia dos resultados. Dentre os vários tipos de RNA existentes, iremos destacar o tipo Long-Short Term Memory (LSTM), devido a sua aplicação na utilização de séries de dados temporais, pois tem como característica a dependência entre as variáveis com relação ao tempo (BROWNLEE, 2018).

Os parâmetros de entrada recebem pesos aleatórios pequenos, então a saída estimada é então comparada com a saída desejada, se houver erro, este é calculado e os pesos sobre os parâmetros de entrada são redistribuídos através da rede, de forma a diminuir o erro. Isso é repetido muitas vezes até que a rede consiga produzir a saída desejada (DEEP LEARNING BOOK, 2019).

Estudos utilizando RNA voltados as questões climáticas podem ser observados em: Santamouris et al. (1999), Mihalakakou et al. (2004), Afzali et al. (2011), Young Lee et al. (2015), OH et al. (2020) entre outros. Os resultados foram comparados com dados medidos e o método de rede neural foi capaz de simular com precisão os dados de temperatura do ar e ilha de calor urbana.

Assim, essas informações podem ser aproveitadas pelos formuladores de políticas ao elaborar planos de mitigação para a ICU. Os pesquisadores enfatizam que para mitigar os efeitos da ICU, são necessárias ferramentas apropriadas e precisas para analisar e prever o comportamento futuro.

Cuiabá-MT, local de estudo desta pesquisa, é conhecida pelo seu rigor climático, com elevadas temperaturas durante todo ano. O IBGE (2020) estimou que a população urbana do município é de 618.124 , indicando aumento de $12 \%$ em 8 anos, refletindo na expansão da malha urbana. Estudos anteriores no município detectaram ilha de calor noturna nas estações do verão e inverno, 
relacionadas com aumento de cobertura do solo impermeável e diminuição de cobertura de vegetação urbana (SANTOS et al., 2012; PAULA et al., 2019).

O objetivo desta pesquisa é estimar a temperatura do ar noturna para a cidade de Cuiabá/MT utilizando Rede Neural do tipo LSTM e posteriormente simular a ilha de calor urbana.

\section{MATERIAL E MÉTODOS}

\section{DELINEAMENTO DA PESQUISA}

Cuiabá-MT, local de estudo desta pesquisa está situada na região sul do estado de Mato Grosso, com altitude média inferior a $200 \mathrm{~m}$, no encontro de três importantes biomas brasileiros: o Pantanal, o Cerrado e a Floresta Amazônica. Registra baixos valores de velocidade do vento, o perfil climático é o tropical continental semi-úmido do tipo Aw segundo a classificação de Köppen, com duas estações bem definidas, uma quente-seca (outono-inverno) e uma quenteúmida (primavera-verão) e máximas diárias de temperatura do ar que oscilam entre $30^{\circ} \mathrm{C}$ e $36^{\circ} \mathrm{C}$ (SANTOS, 2012).

Os dados utilizados foram obtidos em 2011-2012 (SANTOS, 2012) e 2016 (PAULA, 2017) sendo as variáveis temporais (temperatura do ar e umidade relativa do ar) e variáveis espaciais (cobertura do solo), com o objetivo de estimar a temperatura do ar para 2021 utilizando RNA do tipo LSTM.

Para obtenção das variáveis temporais, utilizou-se a metodologia de transecto móvel noturno, que permite avaliar o comportamento da temperatura do ar e umidade relativa do ar em cada intervalo do percurso por meio de sensores que foram instalados em veículos automotores ao longo do trajeto prédeterminado dentro da área de estudo (ARAUJO, et al., 2008). As medições iniciaram a partir das 20 horas, mantendo a velocidade do veículo entre 30 e 40 $\mathrm{km} / \mathrm{h}$, em dias com condições climáticas estáveis, com ventos leves e céu claro (OKE, 2004; AMORIM, 2005; SANTOS \& NOGUEIRA, 2012), conforme tabelas 1 a e $1 \mathrm{~b}$.

Tabela 1a - Período de medição por transectos móveis por SANTOS (2012)

\begin{tabular}{lll}
\hline MÊS & DIA & ESTAÇÃO \\
\hline ABRIL/2011 & $12 / 19 / 26$ & OUTONO \\
\hline MAIO/2011 & $09 / 17 / 26$ & OUTONO \\
\hline JUNHO/2011 & $14 / 16 / 21 / 28$ & OUTONO/INVERNO \\
\hline JULHO/2011 & $07 / 12 / 21 / 26$ & INVERNO \\
\hline AGOSTO/2011 & $08 / 16 / 29 / 30$ & INVERNO \\
\hline SETEMBRO/2011 & $06 / 19 / 25 / 28$ & INVERNO/PRIMAVERA \\
\hline OUTUBRO/2011 & 24 & PRIMAVERA \\
\hline NOVEMBRO/2011 & $09 / 23$ & PRIMAVERA \\
\hline FEVEREIRO/2012 & 28 & VERÃO \\
\hline MARÇO/2012 & $18 / 19$ & VERÃO \\
\hline
\end{tabular}


Tabela 1b - Período de medição por transectos móveis em 2016, realizada por PAULA (2017)

\begin{tabular}{lll}
\hline MẾS & DIA & ESTAÇÃO \\
\hline MARÇO/2016 & $04 / 06 / 18 / 20$ & VERÃO \\
\hline MAIO/2016 & 11 & OUTONO \\
\hline JUNHO/2016 & $06 / 11 / 12$ & OUTONO \\
\hline JULHO/2016 & 12 & INVERNO \\
\hline AGOSTO/2016 & 06 & INVERNO \\
\hline SETEMBRO/2016 & $10 / 15$ & INVERNO \\
\hline OUTUBRO/2016 & $28 / 29$ & PRIMAVERA \\
\hline DEZEMBRO & $11 / 20$ & PRIMAVERA \\
\hline
\end{tabular}

Utilizou-se para armazenamento e coleta de dados um datalogger com Global Positioning System (GPS) para obtenção das coordenadas geográficas: Latitude, Longitude e Altitude, juntamente com o sensor de temperatura do ar e umidade relativa do ar acoplado na janela do veículo com proteção de um abrigo.

Todos os sensores anteriormente a coleta foram calibrados em relação a sensores de referência presentes do núcleo de instrumentação do Programa de Pós-Graduação em Física Ambiental da Universidade Federal de Mato Grosso. Para a validação dos dados, foi utilizado como dados de referência os valores obtidos da estação Automática do INMET (Código A901), localizada na 13a Brigada de Infantaria Motorizada de Cuiabá-MT.

Devido a extensão da área de estudo, optou-se por dividir a coleta de dados em dois transectos: o transecto 1 - Leste/Oeste (Figura 1a) com 56 pontos compreendendo 19,76km, e o transecto 2 - Sul/Norte (Figura 1b) com 35 pontos compreendendo $11,6 \mathrm{~km}$.

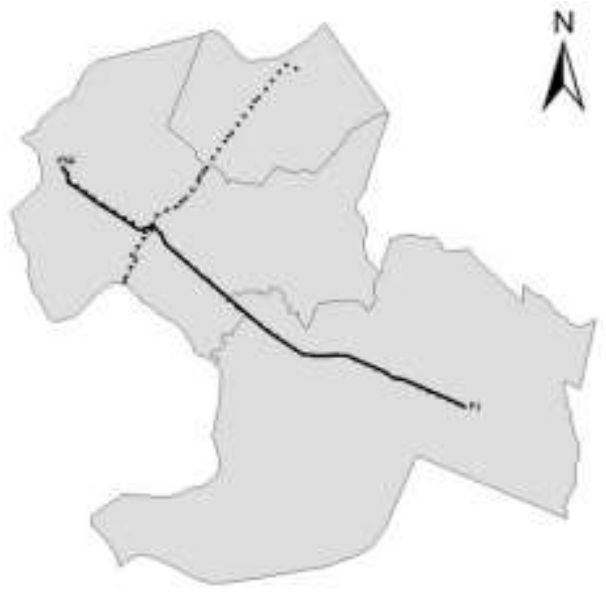

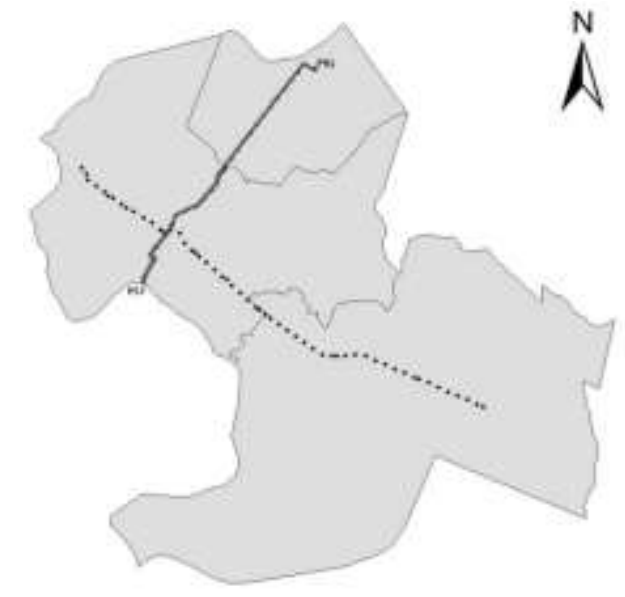

(a)

Figura 1 - Transecto 1, figura 1(a) e transecto 2, figura 1(b).

As anomalias que ocorrem na temperatura do ar são oriundas do aquecimento desigual das diferentes feições do ambiente urbano (ALVES, 2010). Fialho (2012) explica os vários tipos de ilha de calor de acordo com o método 
adotado para mensurá-la, podendo ser: ilha de calor atmosférica, ilha de calor vertical e ilha de calor de superfície.

O tipo de ilha de calor, objeto de estudo nesta pesquisa é a ilha de calor atmosférica, que é definida a partir da diferença de temperatura do ar observada dentro da área urbana. Para o cálculo da ilha de calor urbana, foi obtida a média da temperatura do ar em cada ponto por estação e ano.

No entanto, a magnitude da intensidade das ilhas de calor e seus horários de pico, variam de cidade para cidade, geralmente acontecem cerca de três a quatro horas após o pôr do sol (OKE, 1987). Para a classificação da magnitude da ilha de calor em função da intensidade Brandão (2003) propôs as seguintes classes:

a) Fraca: com diferenças entre 0 a $2{ }^{\circ} \mathrm{C}$;

b) Moderada: com intensidade entre 2 a $4^{\circ} \mathrm{C}$;

c) Forte: entre 4 a $6^{\circ} \mathrm{C}$;

d) Muito Forte: com intensidade maior que $6^{\circ} \mathrm{C}$.

Os cenários para a ICU foram produzidos utilizando software Surfer, onde foram colocados os dados de longitude e latitude relacionado os dados de ICU para cada ponto por estação do ano no período noturno, estimada para 2021.

No caso das variáveis espaciais foi realizada a classificação do solo, utilizou-se a metodologia de OKE (2004) que define como critério a área de alcance do instrumento, sendo a relação de a cada $2 \mathrm{~m}$ de altura que o instrumento esta do solo, o raio de influência é de $200 \mathrm{~m}$. Assim, para os 91 pontos foram determinadas áreas de influência, com isto, foram gerados os mapas temáticos empregando o método de classificação supervisionada e validados por meio da técnica MAXVER (máxima semelhança), utilizando imagens do software Google Earth, obtendo as porcentagens referentes a cada classe de interesse, isto é, cobertura com vegetação rasteira, vegetação arbórea, solo exposto, corpos d'água, área pavimentada e área edificada, para cada um dos anos de estudo.

Para a estimativa da temperatura do ar adotou-se a RNA, que de acordo com Campos et al. (2017) funciona como sistemas computacionais, isto é, neurônios artificiais ou simplesmente nós. E cada nó, é um modelo matemático processando as informações de entrada que serão atribuídos pesos, fornecendo uma saída. Segundo Oliveira et al. (2015) o desempenho da RNA se dá devido a capacidade de aprender a partir do meio, ou seja, a aprendizagem acontece de forma iterativa com base nos ajustes utilizados nos pesos. Os dois autores citados, verificaram em diversas pesquisas que a RNA tem apresentado desempenho superior aos modelos de Regressão.

Dentre as várias arquiteturas de RNA, temos a Rede Neural Recorrente (RNN) que tem como característica a capacidade de modelar sequencias de longo prazo. A LSTM (Figura 2), é um tipo de RNN que tem como procedimento a retropropagação, isto é, são fornecidos parâmetros de entrada com pesos aleatórios pequenos. A saída é então comparada com a saída desejada e seu erro é calculado. Durante o processo, a derivada desse erro é então redistribuida através da rede, e todos os pesos são ajustados de forma a diminuir o erro. Isso é repetido muitas vezes até que a rede converta para produzir a saída desejada (SANTAMOURIS et al., 1999; BROWNLEE, 2018). 


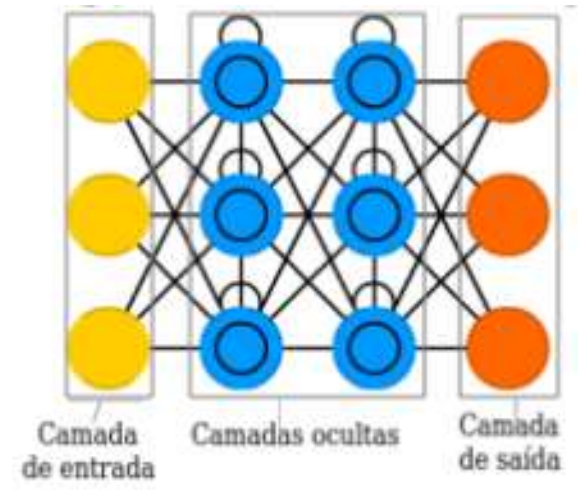

Figura 2-Representação do modelo Stacked LTSM adaptado de Guarienti (2020)

Dentre os modelos de LSTM, o Bidirectional é utilizado em previsão de séries temporais univariadas, de modo que a primeira camada oculta trabalha de forma bidirecional, isto é, permite que a LSTM aprenda a sequência em dois sentidos: entrada para frente e da frente para trás. Além de possuir ótimos resultados de capacidade de predição de series temporais devido a capacidade de persistência da memória e reconhecimento de padrões em sequência de dados (GUARIENTI, 2020).

Os dados foram inicialmente organizados em planilhas eletrônicas separados por estação do ano, em cada planilha foram combinados os dados da seguinte maneira: Data, Longitude e Latitude (UTM - Universal Transversa de Mercator), Hora, Temperatura do ar $\left({ }^{\circ} \mathrm{C}\right)$, umidade relativa do ar $(\%)$, altitude (m), cobertura paisagística, cobertura arbórea, solo exposto, área pavimentada, área edificada e corpos d'água. Em seguida, foram transferidos para o PostgreSQL, sendo possível fazer manipulações utilizando código Structured Query Language (SQL), linguagem de consulta estruturada. Esse fluxo de atividades foi passado para o formato de um diagrama (Figura 3).

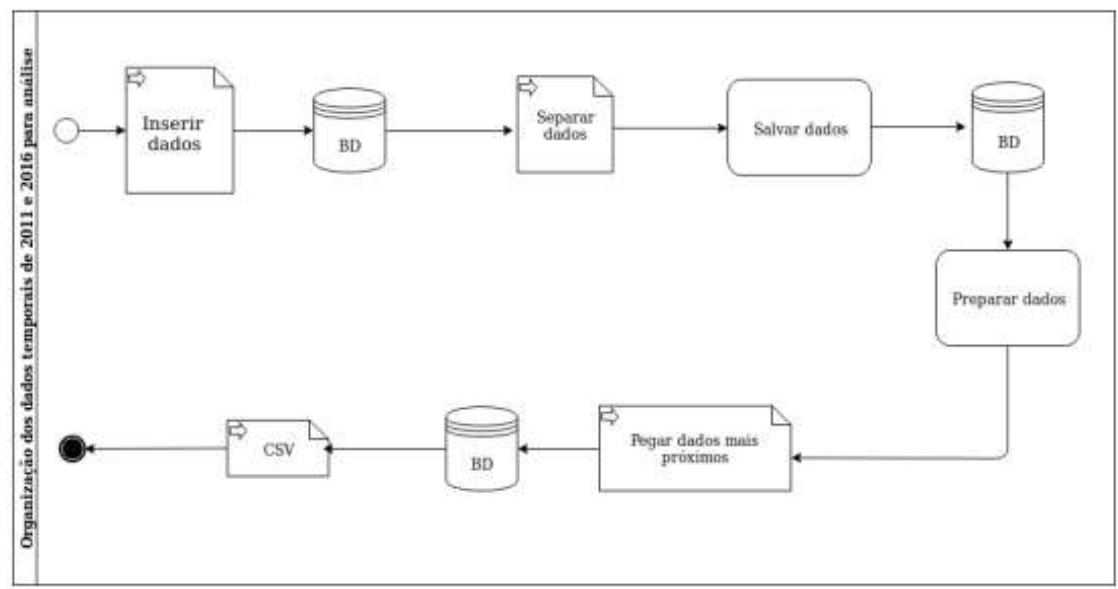

Figura 3- Conjunto de etapas na manipulação do banco de dados adaptado de Guarienti (2020)

Posteriormente, utilizou-se um script para separar e salvar os dados por estações: inverno, outono, primavera e verão. Na etapa seguinte utilizou-se código SQL para gerar um novo banco de dados com os pontos mais próximos de um determinado ponto, ou seja, um ponto de referência no ano de 2016 e os três pontos mais próximos de 2011. Essa busca espacial no transecto foi obtida 
usando um cálculo de proximidade, que considera a distância espacial juntamente com a temporal, sendo que a primeira tem prioridade maior na classificação dos dados. Na sequência, os bancos criados foram exportados para arquivo CSV (Comma Separated Value).

Após o tratamento de todos os dados formou-se, então, os quatro grupos de variáveis que compõem um total de 52 colunas, criando com isso o formato que a Rede Neural precisa como entrada para fazer os cálculos e realizar as predições. O conjunto de dados utilizado foi dividido para realização dos testes de predição, considerando $90 \%$ da amostragem para treinamento e $10 \%$ para teste. A parte de teste utilizada representa o pedaço final dos timestamps, isto é, a parte final do conjunto inteiro de dados analisado em cada caso. Todas as bibliotecas utilizadas estavam em versão compatível com python 3.6.

Foram realizadas quatro combinações (Tabela 2) diferentes para cada estação do ano, para cada combinação de parâmetro salvou-se as informações estatísticas como RMSE, coeficiente de determinação, correlação de Spearman, correlação de Kendall e teste de Wilcoxon.

Tabela 2- Combinação dos parâmetros de treinamento da Rede Neural

\begin{tabular}{cc}
\hline Parâmetro & Valor \\
\hline Épocas & 100 \\
\hline Neurônios & 100 \\
\hline Camadas Ocultas & 4 \\
\hline Batch Size & 32 \\
\hline $\begin{array}{c}\text { Timestamps } \\
\text { anteriores }\end{array}$ & 300 \\
\hline Tipo de LSTM & 1 (stack) \\
\hline
\end{tabular}

Foi utilizado dropout, um recurso de regulação em que parte dos dados são descartados de forma aleatória evitando overfitting, isto é, um tipo de ajustamento forçado da rede aos dados utilizados, o dropout foi de $30 \%$. Para criação do modelo foram testadas diferentes combinações, dessa forma, foi possível salvar o melhor modelo, isto é, o que apresentou existência de uma relação útil entre a variável resposta e a variável regressora, denominado Coeficiente de Determinação $-\mathrm{R}^{2}$. De acordo com vários autores, quanto mais próximo a 1, maior é a relação de dependência entre as variáveis.

O modelo que obteve melhor desempenho foi o escolhido para a simulação da temperatura do ar para o ano de 2021, utilizou-se modelos criados com dados de 2011 e aplicados em dados de 2016. A escolha do ano de 2021 foi feita para seguir o mesmo intervalo de 5 anos. Nessa simulação foram usados modelos e dados de referência da mesma estação, ou seja, no modelo gerado a partir de dados da primavera 2011 foram aplicados dados da primavera 2016 para simular a temperatura do ar da primavera em 2021. O melhor modelo, foi salvo em arquivo .h5 que guardou os pesos utilizados na Rede Neural.

\section{RESULTADOS E DISCUSSÕES}

Apresentam-se aqui os resultados obtidos na criação do melhor modelo para cada estação do ano de 2011-2012 para prever 2016 conforme Tabela 3. 
Tabela 3 - Comparação estatística dos melhores modelos previstos para cada estação do ano

\begin{tabular}{lllllll}
\hline Estação & $\mathbf{R}^{\mathbf{2}}$ & MSE & RMSE & $\begin{array}{l}\text { Teste de } \\
\text { Wilcoxon } \\
\text { (p-value) }\end{array}$ & $\begin{array}{l}\text { Correlação } \\
\text { de Kendall } \\
\text { (p-value) }\end{array}$ & $\begin{array}{l}\text { Correlação } \\
\text { de } \\
\text { Spearman } \\
\text { (p-value) }\end{array}$ \\
\hline Outono & 0,88 & 0,040 & 0,020 & 0,00 & 0,00 & 0,00 \\
\hline Inverno & 0,97 & 0,006 & 0,082 & 0,00 & 0,00 & 0,00 \\
\hline Primavera & 0,94 & 0,003 & 0,058 & 0,00 & 0,00 & 0,00 \\
\hline Verão & 0,99 & 0,007 & 0,082 & 0,00 & 0,00 & 0,00 \\
\hline
\end{tabular}

O melhor modelo de outono (Figura 4a) apresentou $\mathrm{R}^{2} 0,88$ e o de inverno (Figura 4b) obteve $R^{2} 0,972$ nos dados de teste. $O$ melhor modelo da primavera (Figura 4c) obteve $R^{2}$ 0,94 e para o verão (Figura 4d) alcançou $R^{2}$ 0,99 . As diferenças entre os dados medidos e estimados nas estações variaram entre $0,01^{\circ} \mathrm{C}$ a $0,20^{\circ} \mathrm{C}$. Indicando em ambos os modelos a alta relação entre os dados medidos e previstos. Corroborando com a pesquisa de Afzali et al. (2011) que encontraram boa concordância entre os valores previstos e medidos, na ordem de $\mathrm{R}^{2}$ 0,97 a 0,98 utilizando RNA.

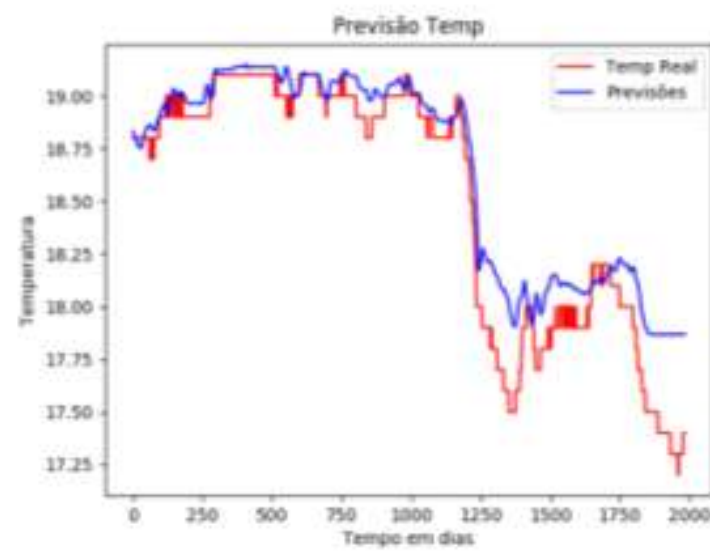

a)


c)

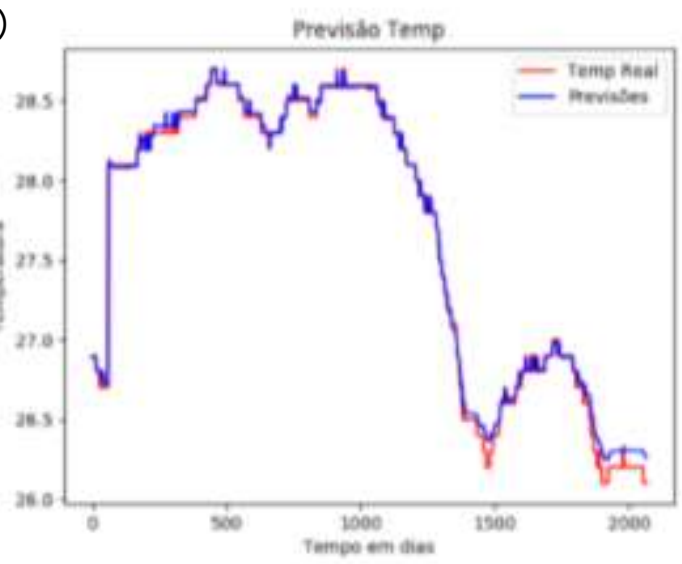

d)

Figura 4 - Modelos de Outono Figura 4(a), Inverno Figura 4(b), Primavera Figura 4(c) de 2011 para 2016 e Verão Figura 4(d) de 2012 para 2016 adaptado de Guarienti (2020) 
A partir da comparação entre os modelos com relação ao $R^{2}$, observou-se que o modelo que está mais distante de 1 , é o outono com $R^{2} 0,88$, seguido da primavera com $\mathrm{R}^{2}$ 0,94. Estudos na área de climatologia em Cuiabá, destacam que os meses de abril e outubro são caracterizados como de transição do período úmido para o seco e do seco para o úmido, devido a influência da massa tropical continental que provoca instabilidade na região (CALLEJAS, 2012), são meses que fazem parte da estação de outono e primavera, respectivamente.

As estações que apresentaram melhor coeficiente de determinação foram inverno com $R^{2}$ 0,97 e o verão com $R^{2}$ 0,99. O inverno manifesta baixa umidade do ar, o que influencia em altas amplitudes térmicas diárias e aumento da temperatura máxima. O verão, tem como característica ser uma estação quente-úmida, período de maior precipitação pluviométrica na região, favorecendo a estabilidade da temperatura do ar (CALLEJAS, 2012).

Logo, os modelos gerados a partir dos dados de 2011 para prever 2016 têm relação útil elevada com as variáveis preditoras, de acordo com os respectivos coeficientes de determinação, podendo ser utilizados para a estimativa da temperatura do ar para 2021. Demonstrando a alta capacidade de predição da LSTM a partir de dados temporais, sendo possível a utilização de dados microclimáticos para simulação dos cenários futuros de temperatura do ar.

A partir do modelo criado para o outono, elaborou-se os cenários tanto para a temperatura do ar como para a ilha de calor urbana, conforme tabela 4. A temperatura do ar indica amplitude de $9,83^{\circ} \mathrm{C}$, refletindo no comportamento da ilha de calor urbana com média atingindo $5,76^{\circ} \mathrm{C}$, apontando que algumas áreas da cidade poderão estar até $10^{\circ} \mathrm{C}$ mais aquecidas que outras.

Tabela 4 - Temperatura do ar (Tar) medida no outono em 2011 e 2016, e a estimada para 2021

\begin{tabular}{llll}
\hline Outono & $\mathbf{2 0 1 1}$ & $\mathbf{2 0 1 6}$ & $\mathbf{2 0 2 1}$ \\
\hline Tar Mínima $\left({ }^{\circ} \mathrm{C}\right)$ & 24,91 & 21,61 & 18,42 \\
\hline Tar Máxima $\left({ }^{\circ} \mathrm{C}\right)$ & 27,50 & 26,30 & 28,25 \\
\hline Tar Média $\left({ }^{\circ} \mathrm{C}\right)$ & 26,31 & 23,61 & 24,18 \\
\hline
\end{tabular}

Na simulação de cenário da ICU para a estação do outono (Figura 5) de 2021 estima-se que dentre a área de estudo, 01 ponto em ICU fraca, 17 pontos em ICU moderada com pico de $3,98^{\circ} \mathrm{C}, 34$ pontos em ICU forte com pico de $5,73^{\circ} \mathrm{C}$ e 39 pontos com ICU muito forte com pico de $9,83^{\circ} \mathrm{C}$. 


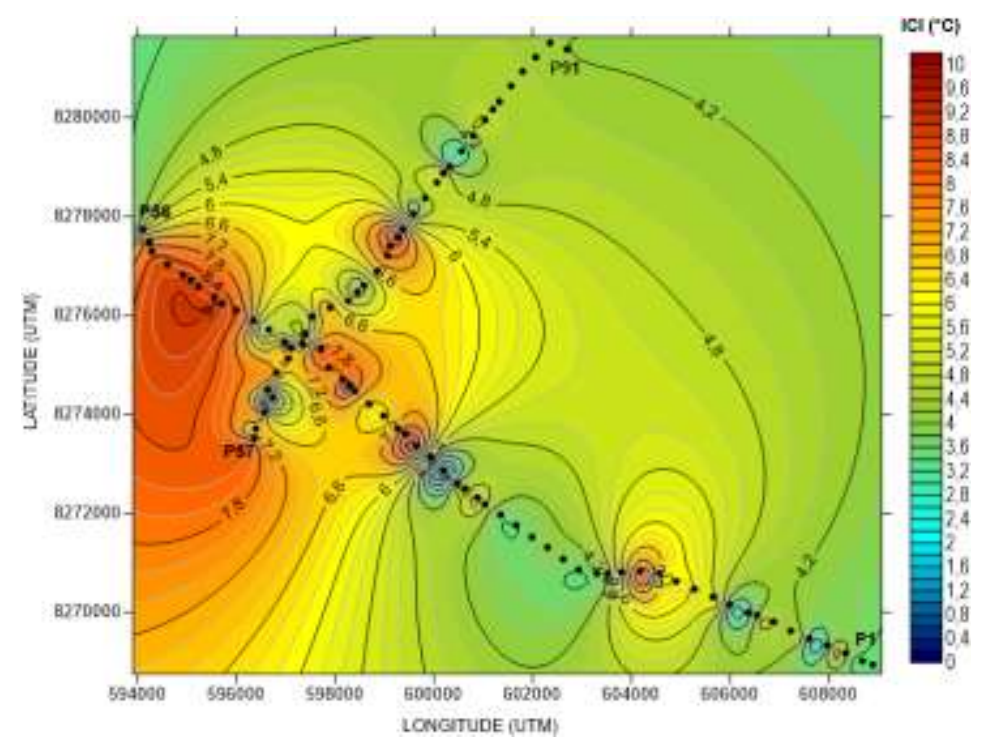

Figura 5 - Cenário estimado da ilha de calor urbana para o outono de 2021 nos transectos

Na tabela 5 observa-se no inverno de 2011 a temperatura do ar média de $28,7^{\circ} \mathrm{C}$, em 2016 de $29,1^{\circ} \mathrm{C}$, já em 2021 estima-se que será de $29,7^{\circ} \mathrm{C}$. Destaca-se que o inverno poderá ter elevação de temperatura do ar média de até $1^{\circ} \mathrm{C}$ em 10 anos e ICU média prevista acima de $3^{\circ} \mathrm{C}$. Nesta estação são observados baixos registros de precipitação o que corrobora para as elevadas amplitudes térmicas e aumento da temperatura do ar máxima.

Tabela 5 - Temperatura do ar (Tar) medida no Inverno em 2011 e 2016, e a estimada para 2021

\begin{tabular}{cccc}
\hline Inverno & $\mathbf{2 0 1 1}$ & $\mathbf{2 0 1 6}$ & $\mathbf{2 0 2 1}$ \\
\hline Tar Mínima $\left({ }^{\circ} \mathrm{C}\right)$ & 27,16 & 26,43 & 26,20 \\
\hline Tar Máxima $\left({ }^{\circ} \mathrm{C}\right)$ & 29,91 & 30,43 & 31,67 \\
\hline Tar Média $\left({ }^{\circ} \mathrm{C}\right)$ & 28,66 & 29,08 & 29,72
\end{tabular}

No inverno (Figura 6) o prognóstico para a ICU será de ICU fraca em 10 pontos com pico de $1,82^{\circ} \mathrm{C}$, moderada em 42 pontos com pico de $3,96^{\circ} \mathrm{C}$ e forte em 39 pontos com pico de $5,47^{\circ} \mathrm{C}$. 


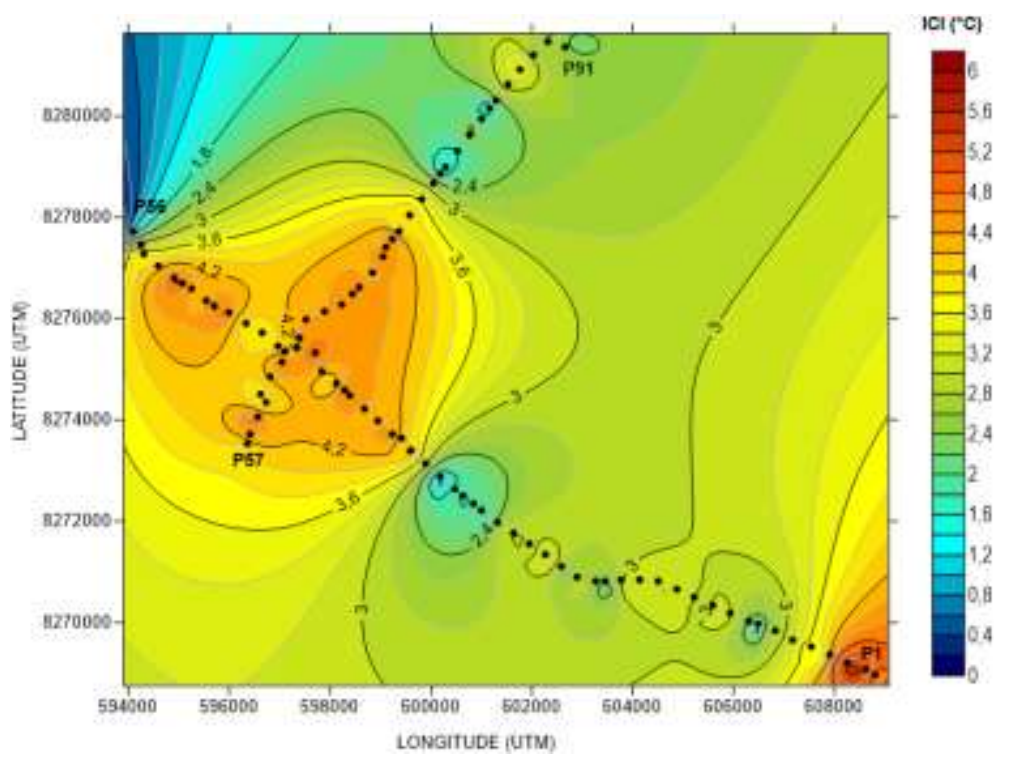

Figura 6 - Cenário estimado da ilha de calor urbana para o inverno de 2021 nos transectos

De acordo com a tabela 6, observa-se a temperatura do ar medida na primavera de cada ano e a estimada para 2021, a partir do modelo gerado. $\mathrm{Na}$ primavera de 2011 a temperatura do ar média é de $30,9^{\circ} \mathrm{C}$, em 2016 de $27,4^{\circ} \mathrm{C}$ e em 2021 estima-se média de $27,7^{\circ} \mathrm{C}$, com ICU média esperada é de $2^{\circ} \mathrm{C}$. Contudo, esta é a única estação que apresenta diminuição de Tar média de $3,2^{\circ} \mathrm{C}$ em 10 anos.

Tabela 6 - Temperatura do ar (Tar) medida na primavera em 2011 e 2016, e a estimada para 2021

\begin{tabular}{cccc}
\hline Primavera & $\mathbf{2 0 1 1}$ & $\mathbf{2 0 1 6}$ & $\mathbf{2 0 2 1}$ \\
\hline Tar Mínima $\left({ }^{\circ} \mathrm{C}\right)$ & 29,53 & 25,79 & 25,64 \\
\hline Tar Máxima $\left({ }^{\circ} \mathrm{C}\right)$ & 31,82 & 28,71 & 29,70 \\
\hline Tar Média $\left({ }^{\circ} \mathrm{C}\right)$ & 30,87 & 27,41 & 27,67 \\
\hline
\end{tabular}

O cenário para a primavera (Figura 7 ), estima média de $2,03^{\circ} \mathrm{C}$ para ilha de calor urbana, que poderá manifestar ICU fraca em 40 pontos e moderada em 51 pontos com pico de $3,43^{\circ} \mathrm{C}$. 


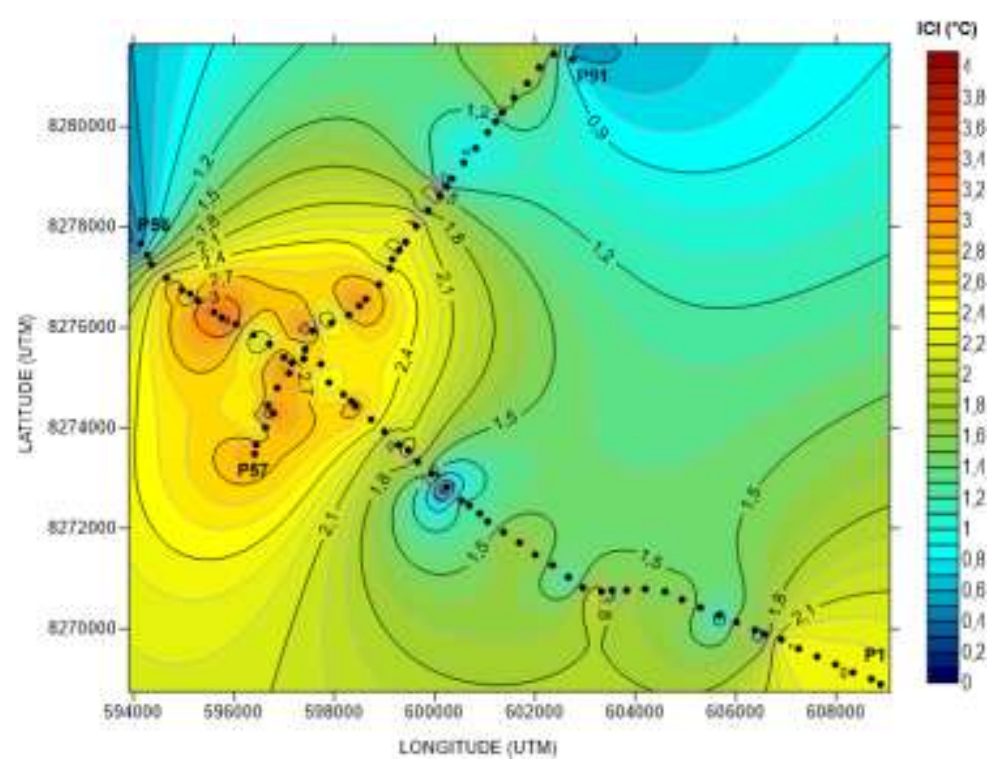

Figura 7 - Cenário estimado da ilha de calor urbana para a primavera de 2021 nos transectos

Conforme a tabela 7, pode-se observar a temperatura do ar medida no verão de cada ano e a estimada para 2021, a partir do modelo gerado. Em 2012 a temperatura do ar média de $27,8^{\circ} \mathrm{C}$, em 2016 média de $28,3^{\circ} \mathrm{C}$ e em 2021 estima-se média de $28,5^{\circ} \mathrm{C}$. Observa-se que ICU média desta estação será de até $1,74^{\circ} \mathrm{C}$ e aumento da temperatura do ar de até $0,5^{\circ} \mathrm{C}$ em 5 anos e de $0,7^{\circ} \mathrm{C}$ em 10 anos.

Tabela 7 - Temperatura do ar (Tar) medida no verão em 2012 e 2016, e a estimada para 2021

\begin{tabular}{cccc}
\hline Verão & $\mathbf{2 0 1 1}$ & $\mathbf{2 0 1 6}$ & $\mathbf{2 0 2 1}$ \\
\hline Tar Mínima $\left({ }^{\circ} \mathrm{C}\right)$ & 26,31 & 26,72 & 26,71 \\
\hline Tar Máxima $\left({ }^{\circ} \mathrm{C}\right)$ & 28,61 & 29,36 & 29,81 \\
\hline Tar Média $\left({ }^{\circ} \mathrm{C}\right)$ & 27,79 & 28,30 & 28,45
\end{tabular}

O cenário para verão (Figura 8) de 2021 estima para a ilha de calor urbana poderá registrar média de $1,74^{\circ} \mathrm{C}$, manifestando ICU fraca em 49 pontos e moderada em 42 pontos com pico de $3,10^{\circ} \mathrm{C}$. 


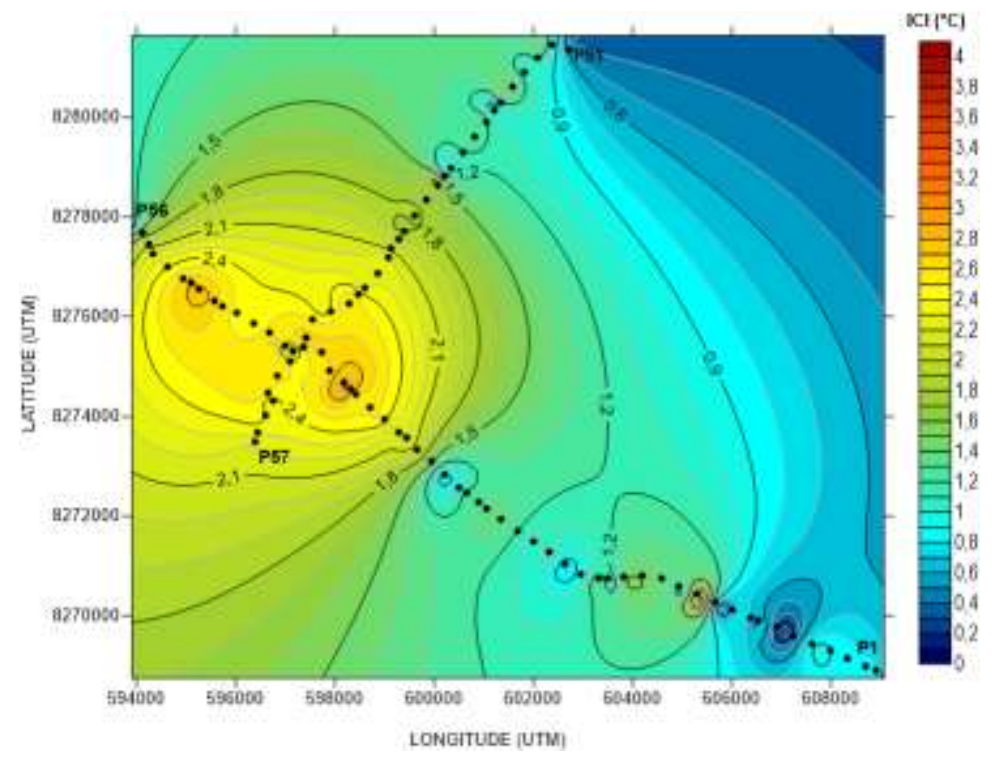

Figura 8 - Cenário estimado da ilha de calor urbana para o verão de 2021 nos transectos

Santamouris et al. (1999) utilizando RNA para estimar temperatura do ar e ilha de calor urbana, relatam que na maioria dos casos as diferenças de temperatura flutuaram entre 0,28 a $0,52^{\circ} \mathrm{C}$, muito próximo com as diferenças encontradas no inverno, primavera e verão em relação a 2016, isto é, o ano que foi utilizado para treinar e estimar a rede. As diferenças estimadas flutuaram entre 0,15 a $0,64^{\circ} \mathrm{C}$, devendo ser consideradas por se tratarem de dados microclimáticos.

Oh et al. (2020) utilizando RNA para analisar ICU e Tar observam que a temperatura do ar tendia a aumentar e diminuir ao longo dos anos, o mesmo comportamento foi observado em 2011, 2016 e continuando em 2021.

\section{CONCLUSÕES}

Frente ao rigor climático caracteristico de Cuiabá, é importante acompanhar a evolução da intensidade das ilhas de calor noturnas encontradas no município, principalmente devido aos efeitos sentidos pela população. Neste sentido o objetivo deste artigo foi de estimar a temperatura do ar e posteriormente a ilha de calor urbana para 2021, utilizando Rede Neural Artificial.

Aplicando dados microclimáticos noturnos de Temperatura do ar e Umidade relativa do ar de cada estação do ano, compreendendo os anos de 2011/2012 e 2016, além de dados espaciais de cobertura do solo de cada ano (paisagística, arbórea, solo exposto, área pavimentada, área edificada e água) a partir de imagens do Google Earth.

Assim, o melhor modelo de outono apresentou $\mathrm{R}^{2} 0,88$ e o de inverno obteve $R^{2}$ 0,972 nos dados de teste. A primavera obteve $R^{2}$ 0,94 e para o verão alcançou $R^{2} 0,99$. As diferenças entre os dados de Temperatura do ar medidos $e$ estimados nas estações variaram entre $0,01^{\circ} \mathrm{C}$ a $0,20^{\circ} \mathrm{C}$, indicando que em todo os modelos à alta relação entre os dados medidos e previstos. 
Estima-se para 2021, na estação do outono Temperatura do ar média de $24,18^{\circ} \mathrm{C}$ e ICU média de $5,76^{\circ} \mathrm{C}$, seguido do Inverno Tar média de $29,72^{\circ} \mathrm{C}$ e ICU média de $3,52^{\circ} \mathrm{C}$. Já para primavera e o verão estima-se Tar média de $27,67^{\circ} \mathrm{C}$ e $28,45^{\circ} \mathrm{C}$, respectivamente. Já a ICU média nas estações será de $1,74^{\circ} \mathrm{C}$ no verão e de $2,03^{\circ} \mathrm{C}$ na primavera. Os cenários ainda foram capazes de demonstrar que o inverno poderá manifestar ICI forte em 39 pontos, já o outono além de ICI forte em 34 pontos, poderá atingir ICI muito Forte em 39 pontos.

Os resultados observados apontam tendência de elevação da intensidade das ilhas de calor noturnas em todas as estações do ano na cidade de Cuiabá/MT, o que pode influenciar no aumento de casos de enfermidades pelo aumento da temperatura do ar, além da demanda de energia nas edificações.

Portanto a RNA do tipo LSTM demonstrou bom desempenho na estimativa da Temperatura do ar e consequentemente na Ilha de calor urbana a partir de dados microclimáticos, podendo ser um recurso a ser explorado no planejamento das cidades em relação as mudanças climáticas.

\section{AGRADECIMENTOS} pesquisa.

Agradecemos a CAPES pelo apoio financeiro durante a realização desta

\section{REFERÊNCIAS}

AFZALI, M.; AFSANEH, A.; ZAHEDI, G. Ambienta ir temperature forescasting using artificial neural network approach. International Conference on Environmental and Computer Science. p.176-180, 2011.

BASU, R. Relation beteen Elevated Ambient Temperature and Mortality: A Review of the Epidemiologic Evidence. Epidemiologic Review 24, 190-202 (2002).

BASU, R. High ambient temperature and mortality of epidemiollogic studies from 2001 to 2008. Environmental Healht, 8 (2009).

BROWNLEE, J. Long Short-Term Memory Networks with Python: Develop Sequence Prediction Models with Deep Learning.2018.

CALLEJAS, I. A. Avaliação temporal do balanço de energia em ambientes urbanos na cidade de Cuiabá-MT. Tese (Doutorado) - Programa de PósGraduação em Física Ambiental - Universidade de Mato Grosso, 242f. 2012.

CAMPOS, B. P. F.; SILVA, G. F. da; BINOTI, D. H. B.; MENDONÇA, A. R. de; LEITE, H. G. Descrição do perfil do tronco de árvores em plantios de diferentes espécies por meio de redes neurais artificiais. Pesquisa Florestal Brasileira, v. 37, n. 90, p. 99-107, 2017.

Data Science Academy. Deep Learning Book, 2019. Disponível em: <http://www.deeplearningbook.com.br/>. Acesso em: 10 Abril. 2020.

DEBIAZI, P. R.; SOUZA, L. C. L. Contribuição de parâmetros do entorno urbano sobre o ambiente térmico de um campus universitário. Ambiente Construído, Porto Alegre, V. 17, n. 4, 2017. p.215-232. 
DOYON, B.; BELANGER, D.; GLOSSELIN, P. The potentiall impacto $f$ Climate change on anual and seasonal mortality for three cities in Quebec, Canada. International Journal of Health Geographics 7, 23 (2008).

DUARTE, D. H. S. O impacto da vegetação no microclima em cidades adensadas e seu papel na adaptação aos fenômenos de aquecimento urbano. Tese (Livre Docência) - Departamento de Tecnologia da Arquitetura - Universidade de São Paulo. São Paulo, 167f. 2015.

IBGE - Instituto Brasileiro de Geogradia e Estatistica. Disponivel: https://www.ibge.gov.br/cidades-e-estados/mt/cuiaba.html. Acesso em: abr.2020.

IPCC - INTERGOVENMENTAL PANEL ON CLIMATE CHANGE (IPCC). Climate Change 2014: Mitigation of Climate Change. IPCC Working Group III Contribution to AR5. 2014b.

GUARIENTI, C. E. Modelagem da temperatura do ar em transecto urbano utilizando LSTM. Tese (Doutorado) - Programa de Pós-Graduação em Física Ambiental - Universidade de Mato Grosso, 88f. 2020.

LEE, Y. Y.; KIM, J. T.; YUN, G. Y. The neural network predictive model for heat island. Intensity in Seoul. Energy and Buildings. p. 353-361, 2015.

LOPES, A. T.; AGUIAR, E. de; SOUZA, A. F. D.; OLIVEIRA-SANTOS, T. Facial expression recognition with convolutional neural networks: coping with few data and the training sample order. Pattern Recognition, Elsevier, v. 61, p. 610-628, 2017

MIHALAKAKOU, G.; SANTAMOURIS, M.; PAPANIKOLAOU, N.; CARTALIS, C.; TSANGRASSOULIS, A. Simulation of the urban heat island phenomenon in mediterranean climates. Pure and Applied Geophysics. p.429-451, 2004.

SANTAMOURIS, M.; MIHALAKAKOU. G.; PAPANIKOLAOU, N.; ASIMAKOPOULOS, D. N. A neural network approach for modeling the heat island phenomenon in urban áreas during the summer period. Geophysical research letters. v. 26, n. 3, p.337-349, 1999.

SANTOS, F. M. M.; NOGUEIRA, M. C. J. A. Análise da influência da ocupação do solo na variação termo-higrométrica por meio de transectos noturnos em Cuiabá-MT. Caminhos de Geografia. v.13, n. 41, p.187-194, 2012.

OH, J.; NGARAMBE, J.; DUHIRWE, P. N. Z.; GEUN, Y. Y.; SANTAMOURIS, M. Usin deep-learning to forecast the magnitude and charcateistics of urban heat island. In Seoul, Korea. Scientific Reports, feb.2020.

ONU - Organização das Nações Unidas. Disponível em: https://news.un.org/pt/story/2019/02/166070. Acesso em: abr.2020.

OKE, T. R. City Size and the Urban Heat Island. Atmospheric Environment, v. 7, n. 8, p. 769-779, ago. 1973

OKE, T. R. Initial guidance to obtain representative meteorological observation at urban sites. Geneva: WMO. 2004.

PARAVANTIS, J.; SANTAMOURIS, M.; CARTALIS, C.; EFTHMIOU, C.; KONTOULIS, N. Mortality associated with high ambiente temperatures, 
heatwaves, and the Urban Heat Island in Athens, Greece. Sustainabillity, 9, 606 (20170).

PAULA, D. C. J. Análise termohigrométrica pós intervenções urbanas em CuiabáMT. Cuiabá, 2017. 106f. Dissertação (Mestrado em Física Ambiental) - Instituto de Física, Programa de Pós-Graduação em Física Ambiental, Universidade Federal de Mato Grosso. Cuiabá, 2017.

PAULA, D. C. J.; SOUZA, N. S.; MIRANDA, S. A.; NOGUEIRA, M. C. J. A.; SANTOS, F. M. M. Evolução do fenômeno de ilha de calor em cidade de médio porte na região centro-oeste do Brasil. Brazilian Journal of Development. V.5, $\mathrm{n}$. 8, aug. 2019. p. 11835-11845. ISSN 2525-8761.

ROCHA, L. M. V.; SOUZA, L. C. L. Contribuição da Vegetação e Permeabilidade do Solo Para o Ambiente Térmico em Avenidas de Fundo de Vale. In: ENCONTRO NACIONAL SOBRE CONFORTO NO AMBIENTE CONSTRUÍDO, Búzios, 2011. Anais... Búzios, 2011 